\title{
RUTINAS DE LA EXPERIENCIA COMÚN. EL ARTISTA SPINOZIANO COMO PRODUCTOR
}

Routines of Common Experience. The Spinozian Artist as Producer

\author{
DIEGOTATIÁN \\ Universidad Nacional de Córdoba-CONICET (Argentina) \\ diegotatian@gmail.com
}

Resumen

El presente trabajo explora el estatuto del arte en la filosofía de Spinoza (aspecto poco estudiado por la crítica), en el marco de la inversión copernicana que da origen a la estética (las "cualidades secundarias" no son propiedades de los objetos sino efectos en los sujetos que perciben) y del barroco holandés. Si bien el pensamiento spinozista se inscribe en la conversión antropológica, en donde lo bello resulta ser un efecto en el sujeto y no una cualidad de los objetos, su comprensión del arte es inasimilable a la "estética" como ámbito diferenciado y autónomo que se consolida en el siglo XVIII, y más bien concibe el arte integrado a la vida y a la experiencia común -a la vez que, en cuanto praxis de origen corporal al alcance de cualquiera, presenta puntos de contacto con las vanguardias históricas del siglo $\mathrm{XX}$-. Spinoza, según se propone en este texto, concibe la producción de "obras de arte" menos como un hecho estético que como una actividad corporal éticamente orientada a la vida buena.

Palabras clave: Spinoza; arte; estética; barroco; cuerpo.

\begin{abstract}
The present work explores the status of art in the philosophy of Spinoza (aspect scarcely studied by critics), within the framework of the Copernican revolution that gives rise to aesthetics (the "secondary qualities" are not qualities of objects but effects in the subjects who perceive) and the Dutch Baroque. Although the Spinozist thought is inscribed in the anthropological conversion by virtue of which beauty turns out to be an effect on the subject and not a property of objects, its understanding of art is unassimilable to "aesthetics" as a differentiated and autonomous area that it was consolidated in the eighteenth century, and rather conceived art integrated to life and common experience -at the same time, as praxis of bodily origin within the reach of anyone, presents points of contact with the historical avant-gardes of the twentieth century-. Spinoza conceives the production of "artworks" less as an aesthetic fact than as a body activity ethically oriented to the good life.
\end{abstract}

Key words: Spinoza; art; esthetic; baroque; body. 


\section{LA INVERSIÓN ESTÉTICA}

Aesthetica (1750) de Baumgarten, Historia del arte en la Antigüedad (1764) de Winckelmann, Salones (1759) de Diderot, son los textos que en el Siglo de las Luces pueden ser considerados fundantes de la disciplina que desde entonces llamamos "estética", por cuanto resultan emblemáticos de los tres elementos principales de la llamada "autonomía del arte": la conversión de la filosofía del arte en una estética propiamente dicha; la formalización en cuanto disciplina de la historia del arte, y la constitución de la crítica (Bozal, 1996, p. 17 ss.). Se verifica -en el caso del arte- un proceso de secularización que se inscribe en ese más vasto conjunto de acontecimientos consistente en la separación del orden terrenal y el orden celestial, que en términos histórico-políticos remonta a Maquiavelo. En el capítulo IX del Laocoonte (1766), escribe Lessing:

Solo quisiera dar el nombre de obras de arte a aquellas en las que el artista se ha podido manifestar como tal, es decir aquellas en que la belleza ha sido para él su primera y última intención. Todas las demás obras en las que pueden verse huellas demasiado claras de convenciones religiosas, no merecen este nombre, porque en ellas el arte no ha trabajado por sí mismo sino como mero auxiliar de la religión, la cual... atiende más a lo simbólico que a lo bello (Lessing, 1977, p. 124).

Tomado al pie de la letra, el pasaje de Lessing significa un rechazo de casi todo el arte medieval y de buena parte del arte producido a lo largo de la historia occidental. La autonomía del arte respecto de la religión -el correlativo surgimiento del gusto, la crítica, el genio; de un sujeto capaz de aisthesis y de placer estético en la recepción de ciertos objetos- es uno de los factores fundamentales de la modernidad, y se articula a la autonomía de la esfera política respecto de la moral y de la filosofía respecto de la teología; así como al subjetivismo que redundará en la moral del sentimiento de Hume y la "revolución copernicana" de la filosofía trascendental -o más bien que desemboca en ella-. La estética comporta pues, no solo la formación de dominios diferenciados o nuevos, sino también una transformación antropológica que pone en marcha la interrogación por el conocimiento, el placer, la creación, y las facultades que intervienen en ellos.

El pensamiento de Spinoza (junto al de Kepler, Galileo, Descartes, Hobbes) se inscribe en los comienzos de la inversión que destrona el ideal de belleza y su objetividad, para considerar que "belleza" es solo un nombre que da cuenta de un efecto en el sujeto -o bien, que no remite a nada que corresponda al objeto afectante, sino a la estructura del sujeto afectado-. En tanto teoría de la sensibilidad, la "estética" expresa las leyes del cuerpo en su relación con otros cuerpos que actúan sobre él. En dos conocidas cartas a Oldenburg y a Hugo Boxel, respectivamente, Spinoza explicita lo que había afirmado en 
el Apéndice de Ética I: la belleza nada tiene que ver con la naturaleza de las cosas; la adjudicación a ella es un derivado del prejuicio de la finalidad (al igual que el bien, el mal, el vituperio, la alabanza, el mérito, el pecado, el orden, la confusión...), que inclina a tomar por realidades lo que es solo un efecto de la imaginación.

En cuanto proporcionan lo esencial de una teoría de la aisthesis, la carta a Oldenburg de 1665, así como la de 1674 a Hugo Boxel, preanuncian la conversión sistemática de la filosofía del arte en "estética" a lo largo del siglo XVIII:

...quisiera advertir que yo no atribuyo a la naturaleza belleza ni deformidad, orden ni confusión. Porque las cosas no se pueden llamar hermosas o deformes, ordenadas o confusas, sino respecto a nuestra imaginación" (Spinoza, 1986a, pp. 235-236); y "La belleza, distinguido señor, no es tanto una cualidad del objeto que se ve, cuanto un efecto en el sujeto que lo ve. Si nuestros ojos fueran más largos o más cortos, o si nuestro temperamento fuera diferente, las cosas que ahora nos parecen bellas, nos parecerían deformes, y las que ahora nos parecen deformes, nos parecerín bellas. Una mano hermosísima, vista en el microscopio, parecerá horrible. Algunas cosas, vistas de lejos son bellas, y vistas de cerca, deformes. De suerte que las cosas, consideradas en sí mismas o en relación a Dios, no son ni bellas ni deformes (Spinoza, 1986a, pp. 319-320).

Pero la destitución de la belleza (del bien, el mal, el orden...) como una cualidad de las cosas, y la consiguiente afirmación de su carácter puramente imaginario (máxima distancia, por tanto, del neoplatonismo, como así también de la naturaleza como "armonía preestablecida"), no significa que sea una pura nada. De manera necesaria, en tanto efecto imaginario, la belleza expresa una verdad del cuerpo humano, su naturaleza, su constitución y sus leyes.

Ahora bien, si la filosofía spinozista de las sensaciones -en sintonía con la de otros filósofos del Seicento- establece las condiciones antropológicas para el nacimiento de la "estética" (palabra que nombra aquí solo la inversión filosófica referida: las sensaciones no expresan cualidades de los objetos sino efectos en los sujetos), la reflexión de Spinoza sobre el arte (o más bien sobre las artes), nada tiene que ver con lo que esta palabra designa desde Kant y el Romanticismo: la autonomía de una esfera del Arte, el libre juego de las facultades, el gusto -y más bien anticipa algunos motivos centrales de las vanguardias históricas que buscaron producir una práctica del "arte" como experiencia común liberada de la institucionalidad con la que fue investido por la modernidad estética-.

\section{SPINOZISMO Y BARROCO}

Una primera consideración remite al vínculo efectivo que Spinoza mantuvo con la cultura de la imagen y el arte de su tiempo -y en particular, de manera conjetural, con los dos más grandes pintores holandeses del siglo XVII: Rembrandt y Vermeer-. La 


\section{Diego Tatián}

investigación de Svletana Alters -entre otras- releva la centralidad del placer de las imágenes en la cultura holandesa del siglo XVII y el impacto en la sensibilidad visual por obra de la reciente tecnología óptica. Los artistas holandeses presentan su pintura como descripción de la realidad visible más que como imitación de acciones humanas -que era lo propio de la pintura italiana-; es descriptiva, no narrativa. En Holanda, la cultura visual y la circulación de imágenes era fundamental para la vida común y para la autoconciencia de la sociedad, de igual manera que fue en el teatro donde la Inglaterra isabelina se representó más completamente a sí misma. En las ciudades holandesas, dice Alters, las imágenes proliferan por doquier: libros, tapices, manteles, muros, azulejos... Y se representa todo, desde flores e insectos hasta nativos del Brasil (Alters, 2016, pp. 30-31). Es seguro que la filosofía spinozista de la imaginación no se halla desvinculada de ese clima cultural de intensa producción visual en el arte y en la experiencia común, como no lo estuvo tampoco de la revolución científica y el estallido de la óptica.

Los pintores holandeses del Seicento tampoco sometían su trabajo a un canon de belleza, sino que orientaban su interés a objetos simples de la vida cotidiana, que revelaban una ubicua eternidad. En tanto la más alta forma de conocimiento, a su vez, la ciencia intuitiva spinozista prescinde de igual manera de abstracciones y toma por objetos las res singulares más comunes -produce así un desmantelamiento de las jerarquías que halla su formulación más plena en la definición 6 de E II: "Por realidad entiendo lo mismo que por perfección" (Spinoza, 1984, p. 109)-.

En un ensayo clásico sobre Rembrandt y Spinoza, Carl Gebhardt sostiene que el pensamiento de la Ética es el resultado de una evolución en la que se inscriben la mística alemana -en particular Angelus Silesius, quien había estudiado en Leiden entre 1644 y 1647 y durante esos años habría tomado contacto con los anabaptistas y otras sectas holandesas; recurriendo a una antigua observación de Leibniz, Gebhardt establece asimismo un vínculo entre el autor del Cherubinischen Wandersmann y la filosofía de Spinoza (Gebhardt, 1929, p. 338)-, el nominalismo, la cultura del Renacimiento, la Reforma, hasta alcanzar su forma más elevada en la "religión de la inmanencia". La tesis central de la interpretación gebhardtiana y su más significativa contribución a la historiografía spinozista, es la que concibe a la de Spinoza como la gran filosofía del barroco. Según esta perspectiva, en ella alcanza su forma más alta y su traducción sistemática la cultura contrarreformista del siglo XVII, la atención y la afirmación de la existencia terrenal que el arte barroco glorifica con la preferencia por el retrato, el paisaje y la naturaleza muerta.

Como el creador de La lección de anatomía del Doctor Tulp, Spinoza sería la expresión del "estilo de una época" - "Llamamos estilo de una época a lo que hace visible este sentimiento de la vida, importando poco que lo percibamos como ley imperante en el arte, en la religión o en la filosofía. Podemos denominar axioma de la unidad estilística a esa regularidad" (Gebhardt, 1929, p. 312)-, la "forma de una época" y la "esencia de 292 | ALPHA No50 (JULIO 2020) PÁGS. 289-307. ISSN 07 16-4254 
una época", que a su vez manifiestan un "sentimiento de la vida" (Lebensgefiihl). Por ello es posible sostener -afirma Gebhardt- que "las categorías del arte de Rembrandt son la mismas que las de la filosofia de Spinoza", pues "el tiempo es una fuerza que se manifiesta en la forma" (Gebhardt, 1929, p. 313)-sin detenerse sin embargo a considerar la conjetura histórica de una recíproca influencia directa entre el pintor y el filósofo, tantas veces imaginada y por muchos indicios también plausible-. Rembrandt, en efecto, vivió en el barrio judío de Ámsterdam durante casi 30 años (entre 1631 y 1660), a pocos metros de la casa paterna de Spinoza. Tuvo trato con su maestro Menasseh ben Israel, de quien hizo un retrato y cuyo libro Piedra gloriosa de la estatua de Nabucodonosor ilustró con cuatro grabados en 1635. Asimismo, según una antigua leyenda -recientemente reproducida por Antonio Damasio (Damasio, 2005, p. 216)-, Spinoza habría sido el modelo usado por Rembrandt para pintar al pequeño David en su cuadro Saúl y David. No obstante, aunque la probabilidad de un vínculo entre el filósofo y el artista es alta, no existe ninguna prueba documental de que se hubieran conocido (Nadler, 2004, p. 117).

Más allá de la conjetura de un vínculo personal que podría haber existido entre ambos, las categorías comunes entre Spinoza y Rembrandt referidas por Gebhardt son, en primer lugar, la infinitud, principio fundamental del que es posible deducir y explicar todos los demás fenómenos característicos del barroco. Si lo propio de la cultura renacentista había sido la pasión por la forma y el límite, el barroco -artístico, religioso o filosófico- es el anhelo de su ruptura y abolición. Asimismo, las nociones de sustancialidad y potencialidad-cuya primacía en la filosofía de Spinoza es tan evidente que su demostración huelga, dice Gebhardt- son definitorias del barroco y comunes con el arte de Rembrandt:

El cuadro de Rembrandt ha nacido de la oscuridad, pero de una oscuridad que es posibilidad de toda luz, del mismo modo que el reposo del barroco supone la posibilidad de todo movimiento. Las visiones luminosas de Rembrandt brotan de esta oscuridad siempre potencial, nunca actual.... En la luz se hace visible el infinito escondido en la oscuridad (Gebhardt, 1929, p. 332).

El Lebensgefiihl que establece su comunidad esencial con el arte de Rembrandt, es exactamente el que separa la filosofía de Spinoza de la metafísica cartesiana y la política de Hobbes.

La tesis de Spinoza como pensador barroco será continuada por Stanislaus von Dunin-Borkowski (1933), en el capítulo titulado "Spinoza als Barockphilosoph" que integra su investigación clásica acerca de los documentos referidos a la vida y la obra del pensador holandés, una cuidada crítica de esta tesis en Mignini (1981, pp. 410-430), a partir de los trabajos de Gebhardt y Dunin-Borkowski, y obligado punto de partida de todos los estudios posteriores que buscan establecer un vínculo entre Spinoza y el barroco. Más recientemente Saverio Ansaldi estudia la presencia de escritores del Siglo de Oro 


\section{Diego Tatián}

español en la filosofía spinozista; no se tratará en su recorrido de decidir si Spinoza fue o no un filósofo barroco, sino de detectar en sus textos la presencia de autores españoles de la época barroca y determinar el uso que hace de ellos y cómo los retoma.

Es decir, se busca allí leer la filosofía de Spinoza a la luz de conceptos de los escritores del barroco español -y en particular los que poseía en su biblioteca (Quevedo, Góngora, Gracián, Saavedra Fajardo...)- que son abordados en su obra. En primer lugar, el concepto de potencia (clave del pensamiento barroco), y luego otros conectados con él: infinito, providencia, deseo, pasión, virtud, multitud, fortuna, ingenium... Ansaldi se propone mostrar cómo ciertos aspectos de la filosofía de Spinoza se constituyen y se definen con, a través y también contra una conceptualización de derivación barroca. Para ello, postula que, en los tres grandes dominios de la ontología, la antropología y la política es posible identificar un "operador conceptual" (respectivamente: infinito, deseo, multitud) que permite establecer una contigüidad teórica y conceptual entre Spinoza y la cultura barroca (Ansaldi, p. 2001).

Entre los estudiosos latinoamericanos, Leiser Madanes encuentra el barroco en la lectura spinozista de la Biblia -en efecto, Spinoza considera aquí a "la Biblia como texto barroco" y la interpreta "según los cánones estéticos con los que el barroco del siglo XVII producía sus propias obras" (Madanes, 2001, p. 155-159)-; en tanto que Cecilia Abdo Ferez lee el Tratado político como libro barroco: a partir de "la dilución de las figuras" que adopta la soberanía en el fondo indeterminado e informe de la multitud; de una "desproporción entre significado y significante" en la noción de imperium; y de la remisión de la obra -en tanto tal non finita a "la historia y la experiencia del lector" para ser completada por él (Abdo Ferez, 2008, pp. 161-170)- por lo demás, ya Lezama Lima había considerado a Spinoza como un autor barroco, junto con Loyola, Rembrandt, El Greco, Rubens, Bach y Leibniz (Lezama Lima, 1993, p. 79).

Otro tanto sucede con el otro gran pintor holandés contemporáneo del filósofo: Vermeer. Como la filosofía intuitiva de los res singulares en Spinoza, la pintura de Vermeer no se aleja de los objetos comunes: experiencia de la eternidad en lo que es singular y cotidiano en tanto expresión de lo que no puede ser imaginado ni representado, a no ser por sus manifestaciones. En una reciente conjetura-o "hipótesis borgiana", como la llama su autor-, Jean-Clet Martin sugiere una sociedad entre el filósofo de Ámsterdam y el pintor de Delft (que habían nacido en el mismo año, 1632), a partir de una indagación de la noción de conatus en tanto vis nativa, "fuerza naciente que irrumpe desde el interior de cada individuo" -y por consiguiente antipódica del principio de inercia, conforme el cual nada tiene fuerza propia y todo sucede por comunicación y transmisión (Martin, 2011, p. 19)-.

La vinculación entre Spinoza y Vermeer podría haberse producido por mediación del llamado "padre de la microbiología", Anton van Leeuwenhaek, como el pintor, también natural de Delft. Al igual que en el caso de Rembrandt, ningún documento 294 | ALPHA No50 (JuLIO 2020) PÁGs. 289-307. ISSN 07 16-4254 
testimonia que Spinoza hubiera tenido una relación con él; no obstante, el autor colige el vínculo por el hecho de que Van Leeuwenhaek construyó más de cuatrocientos microscopios y poco probable que pudiese haber ignorado para ello el trabajo del más célebre pulidor de lentes de Holanda -que, en la vida citadina y comercial, solo en segundo lugar era conocido como filósofo-. Por tanto, concluye Martin, "Van Leeuwenhaek descubre los glóbulos rojos gracias a un microscopio cuyas lentillas había recibido de Spinoza" (Martin, 2011, p. 58). Y consiguientemente barrunta que la provisión de lentes para la cámara obscura con la que se presume trabajaba Vermeer, "una especie de visión del tercer género de conocimiento", pudo provenir del taller spinozista. Aunque tampoco existen pruebas relevantes -a no ser que así sean consideradas sus pinturas mismas- de que Vermeer empleara en realidad una cámara oscura; se trataba de un dispositivo difundido entre los artistas holandeses, desde que en 1622 Constantijn Huygens (padre de Christian y "descubridor" de Rembrandt), adquiere del inventor Cornelius Drebbel un artefacto capaz de proyectar imágenes con la sola luz exterior, que utilizaba -y recomendaba a sus amigos pintores- para pintar.

La "hipótesis borgiana" arroja pues tres sospechas: 1. El astrónomo (pintura cuyo título original había sido El filósofo) no es otro que Spinoza; 2. Las lentes de la camera obscura con la que quizá trabajaba Vermeer habrían sido fabricadas por Spinoza, y el intermediario no sería otro que Van Leeuwenhaek; 3. El escrito perdido sobre el arco iris podría haber tenido que ver con la pintura de Vermeer: en tanto Spinoza habría proporcionado a Vermeer su conocimiento acerca de la óptica, el pintor y su trabajo pudieron suministrar al filósofo la materia para el estudio, hoy perdido, cuyo título era Tratado sobre el arco iris (Martin, 2011, p. 60).

\section{ARTEDE VIVIR}

La cultura y la "experiencia común" holandesas del siglo XVII, son un abierto campo de experimentación visual con nuevos instrumentos que dan lugar a nuevas teorías de la imagen y la imaginación. Para Spinoza, la imaginación no es solo un efecto pasivo sino también una fuerza poiética, una expresión de la Cupiditas y del deseo de perseverar. En su clásico estudio Ars imaginandi (1981), Filippo Mignini indaga de manera minuciosa el estatuto del arte en Spinoza, que no se define por su relación con la belleza sino solo por su relación con la Cupiditas y las leyes del cuerpo. No existe ninguna realidad ni objetividad de la belleza, que es solo una forma de la imaginación. La investigación de Mignini establece una conexión decisiva entre la nueva filosofía de la mente, la irrupción de la óptica y el interés de los filósofos del Seicento -entre estos, Hobbes, Huygens, Leibniz, Descartes, Robert Boyle y los miembros de la Royal Society, por la naturaleza de la luz, las lentes, la estructura retiniana; es decir, por el mecanismo de la visión y su vinculación con el cerebro. 


\section{Diego Tatián}

Las imágenes presentes en la mente nos hacen conocer más la naturaleza del cuerpo afectado que la naturaleza del cuerpo externo afectante (E, IV, 1, esc.; E, III, 14, dem.), pero en sí mismas no contienen error, sino que expresan la potencia de la Mens;

...si el alma, al tiempo que imagina como presentes cosas que no existen supiese que realmente no existen, atribuiría sin duda esa potencia imaginativa a una virtud, y no a un vicio de su naturaleza; sobre todo si esa facultad de imaginar dependiese de su sola naturaleza, esto es..., si esa facultad de imaginar que el alma posee fuese libre (Spinoza, 1984, p, 137).

La imaginación expresa la esencia de la mente y ninguna representación o conocimiento (a excepción del conocimiento de Dios) puede prescindir de ella. Pero expresa asimismo las leyes del cuerpo, en las que tiene su causa. Esa expresión no implica error alguno, a no ser que se encuentre acompañada de un juicio de existencia. Según la carta a Balling del 20 de julio de 1664, "las imágenes son consideradas ya sea como efecto del cuerpo, ya sea como efecto del alma". Desde una perspectiva cualitativa son diversos, mente y cuerpo son a la vez idénticos: expresan lo mismo en absoluto diferenciados.

Pero en Spinoza la cuestión del arte se desplaza de la imaginación y las imágenes a la acción y sus efectos, de las "obras" a la potencia productiva del cuerpo, de la estética a la ética y la práctica política. En su filosofía, la palabra ars aparece diseminada, con significaciones disímiles, casi imposible de ser reducida a una definición. Indica técnicas, oficios, habilidades, la capacidad política y civil en sentido maquiaveliano (arte ad concordiam $)^{1}$, acciones comunes para sustentar la vida (ad vitam sustentandam $)^{2}$, "artes de la paz" (pacis artes) [TP, VII, § 8], "artes de la guerra" (belli artes) [TP, VII, § 22], el "arte militar" (ars militaris) [TP, VIII, § 9], así como lo que llamamos "bellas artes", e incluso un "arte de cuidar el cuerpo" (ars corpus curandi) ${ }^{3}$, un "arte de pensar" (excogitanda ars), etc. ${ }^{4}$. Esta radical indeterminación del "arte" según Spinoza, su

\footnotetext{
1 "Si la naturaleza humana estuviera dispuesta de tal modo que el máximo deseo de los hombres estuviera orientado hacia lo que es más útil, no sería necesario un arte de la concordia y de la lealtad, pero puesto que la naturaleza humana está constituida de un modo por completo diferente, es necesario proporcionar para el Estado un fundamento tal, etc." (Spinoza, 1986b, p. 123).

2 “. ...arar, sembrar, cosechar, moler, cocer, tejer, coser y realizar otras innumerables actividades para mantener la vida, por no mencionar las artes y las ciencias, que también son muy necesarias para el perfeccionamiento de la naturaleza humana y para su felicidad" (Spinoza, 1986c: 157).

3 "De qué manera y por qué método deba perfeccionarse el entendimiento, y mediante qué arte ha de cuidarse el cuerpo a fin de que pueda cumplir rectamente sus funciones..." (Spinoza, 1984, p. 353).

${ }^{4}$ También encontramos acepciones negativas del término, como es el caso de las "artes del lucro" (lucri artes) (Spinoza, 1984,p. 347); de las "artes" en tanto habilidades con las que los políticos - "guiados por el miedo más que por la razón"- tienden trampas a los hombres para prevenir su malicia (Spinoza, 1986b, p. 79); o -en el sentido de "artimañas"- de las "artes" empleadas por los pontífices para alcanzar la primacía de la Iglesia (Spinoza, 1986, pp. 400-401).

296 | AlPHA No50 (Julio 2020) PÁGS. 289-307. ISSN 07 16-4254
} 
insubordinación respecto de las teorías clásicas de la belleza y su irreductibilidad a la estética del gusto relega la cuestión del arte en Spinoza precisamente por su no inscripción en una estética del gusto (p. e., Morrison, 1989: 360) tal y como será elaborada en el siglo XVIII, presenta un altísimo interés -y dialoga de forma anacrónica con parte de la crítica contemporánea de arte, como la de Konrad Fidler o Carl Einstein, quienes rompen con la identificación de arte y belleza, a la vez que con cualquier forma de una estética normativa (Didi-Huberman, 2018, pp. 249-250)-. En cualquiera de sus acepciones, la causa del arte es el deseo. Por consiguiente, el arte humano no es sino una prolongación, una extensión, un avatar del arte con el que la naturaleza produce infinitas cosas en infinitos modos -lo que conlleva un desmantelamiento de toda jerarquía y división (entre artes liberales y artes vulgares o serviles; entre bellas artes y artesanías; entre arte culto y arte popular, etcétera)-. En tanto expresión de la naturaleza, el arte se sustrae de cualquier comprensión suya como hecho humano, demasiado humano, así como también de su determinación hegeliana en tanto manifestación sensible de la idea. En Spinoza, arte es siempre ars vivendi con base en las leyes del cuerpo humano.

Aunque no encontremos en la obra de Spinoza referencias explícitas de Plinio el Viejo, ni la Historia natural forme parte de la biblioteca relevada por el acta notarial que registra sus pertenencias al momento de morir (solo consta en ella un volumen de Plinio el Joven que contiene Epístolas y el Panegírico a Trajano), tenemos allí una fuente posible de la concepción spinozista de ars, y otros probables influjos -entre los cuales la imposibilidad de separar la potentia Naturae y la potentia Dei-. Jacqueline Lagrée, en efecto, remite la asimilación de la potencia de la naturaleza y la potencia de Dios en el TTP a una cita implícita de la Historia natural: "el poder de la naturaleza... es lo que llamamos Dios (naturae potentia idque esse quam deum vocemus)" (Plinio el Viejo, 1995 vol. II, pp. 5, 27) -idea que había sido invocada como estoica por Justo Lipsio en su Physiologia stoicorum (Lagrée, 2004, pp. 84-85 y 166)-. Spinoza reescribe esta línea de Plinio en varios pasajes de su obra, por ejemplo en el capítulo XVI del Tratado teológicopolítico: "el poder de la naturaleza es el mismo poder de Dios (naturae enim potentia ipsa Dei potentia est)" (Spinoza, 1986c, p. 332).

En sentido análogo a como se encontrará en Spinoza,

lo que Plinio entiende por 'artes' (artes) es extensivo a la completa Historia natural; en consecuencia, la noción estética de arte no forma parte de su primera definición. Hay 'arte' cada vez que el hombre utiliza, instrumentaliza, imita o supera a la naturaleza. El 'arte por excelencia, en el texto pliniano, es ante todo la medicina, a la cual la Historia natural consagra sus mejores desarrollos. En cuanto al arte de la pintura -en el sentido en que hoy la entendemos-, solo ocupa una parte del libro XXXV, al final del recorrido de un libro gigantesco (Didi-Huberman, 2018, p. 103). 


\section{Diego Tatián}

El cuerpo humano es el arte de la potencia natural, cuyos productos a su vez -las "bellas artes", pero también, arar, sembrar, moler o tejer según el pasaje de TTP V citado supra- no son sino una extensión. Arte, pues, es la actividad de cualquiera que sucede cada día en la experiencia.

Lorenzo Vinciguerra propone comprender el arte en Spinoza a partir de la noción de "adecuación", es decir de lo que el cuerpo puede hacer "en virtud de las solas leyes de su naturaleza". Normalmente atribuido a la idea, el concepto de adecuación es aquí reorientado hacia el cuerpo para concebir el arte como efecto de su potencia, acción autónoma, práctica corpórea adecuada. Al producir una obra, el cuerpo es su causa adecuada:

Digo que nosotros actuamos, cuando en nosotros o fuera de nosotros se produce algo de lo que somos causa adecuada, esto es, cuando de nuestra naturaleza se sigue algo, en nosotros o fuera de nosotros, que puede ser comprendido clara y distintamente por ella sola. Nos apartamos en este pasaje de la versión de Vidal peña que usamos en la mayoría de los casos y citamos de la traducción de Atilano Domínguez (Spinoza, 2000, p. 126).

Del mismo modo que la "definición adecuada" no remite a la verdad de la idea en sentido extrínseco, sino a la potencia del pensamiento que expresa en su verdad intrínseca, lo mismo debe afirmarse de la esencia del arte: reside en la sola potencia del cuerpo, en la potencia de su acción y de su imaginación (Vinciguerra, 2012, pp. 169-179).

Spinoza concibe al cuerpo como un efecto de arte, en este caso del arte mecánico natural en el que se inscribe la acción humana que designamos con esa palabra: "Y así también, cuando ven la fábrica del cuerpo humano, quedan estupefactos $\mathrm{y}$, porque ignoran la causa de tanto arte, concluyen que está fabricada, no con un arte mecánico, sino divino o sobrenatural..." (Spinoza, 2000, p. 71). El texto fundamental para esta comprensión del arte como efecto del cuerpo, y del arte humano como prolongación del arte de la naturaleza, es el pasaje del escolio de E, III, 2:

Y el hecho es que nadie, hasta ahora, ha determinado lo que puede el cuerpo, es decir, a nadie ha enseñado la experiencia, hasta ahora, qué es lo que puede hacer el cuerpo en virtud de las solas leyes de su naturaleza... Pues nadie hasta ahora ha conocido la fábrica del cuerpo... Dirán, empero, que no es posible que de las solas leyes de la naturaleza, considerada como puramente corpórea, surjan las causas de los edificios, las pinturas y cosas de índole similar (que se producen solo en virtud del arte humano), y que el cuerpo humano, si no estuviera determinado y orientado por el alma, no sería capaz de edificar un templo. Pero ya he mostrado que ignoran lo que puede un cuerpo... Añado aquí el ejemplo de la fábrica del cuerpo humano, que supera con mucho en artificio a todas las cosas fabricadas por el arte de los hombres (Spinoza, 1984, p. 186). 
Hay una espontánea artisticidad o poieticidad de la vida humana; una potencia productiva de ideas, objetos y vínculos que se explica por la vida que se expande, no por la muerte que impone su régimen de pasiones tristes. No es por consiguiente el arte un imperium in imperio sino ejercicio efectivo del derecho natural conforme una modalidad que requiere de la vida en sociedad. Spinoza comparte la idea hobbesiana del estado de naturaleza como una situación de precariedad extrema en la que nada puede prosperar (es decir, una condición en la que

no existe oportunidad para la industria, ya que su fruto es incierto... no hay cultivo de la tierra, ni navegación, ni uso de los artículos que pueden ser importados por mar, ni construcciones confortables, ni instrumentos para mover y remover las cosas que requieren mucha fuerza, ni conocimiento de la faz de la tierra, ni cómputo del tiempo, ni artes, ni letras, ni sociedad... (Hobbes, 1998, pp. 103-104).

Sin sociedad, también para Spinoza la vida es incierta y el arte en todos sus sentidos se desvanece: "La sociedad es sumamente útil e igualmente necesaria... a menos que los hombres quieran colaborar unos con otros, les faltará arte y tiempo para sostenerse y conservarse lo mejor posible..." (Spinoza, 1986c, p. 157).

En la sociedad spinozista, en efecto, arte es la actividad común que de manera natural realizan los seres humanos en su rutina de conservarse, en virtud de ello "muchas cosas difíciles se hacen fáciles" (Spinoza, 1988, p. 80) -acaso también las praeclara, "tan difíciles como raras" según la última proposición de la Ética, encuentren en el arte una vía de acceso por la experiencia sensible en el orden de los cuerpos- ${ }^{5}$. Si esa sociedad deviene democrática, es decir una forma de vida colectiva donde la potencia individual y común obtiene condiciones para su manifestación siempre más plena, no habrá en ella, estrictamente, "artistas". O lo que es igual: en la democracia spinozista no hay nadie que no lo sea, pues el arte no está allí separado de la vida (término que para Spinoza nunca es en estricto sentido biológico, como no lo es su conservación: vida es aquí siempre vida humana $^{6}$ ) ni adopta una función compensatoria. Arte es en ese caso lo que resulta de una potencia individual y colectiva del cuerpo activo, como la filosofía es potencia del pensamiento, que tiene, también ella, su causa en el deseo. O dicho con un término más propio: el arte no es autónomo, ni una esfera separada, ni trascendente a la experiencia común sino inmanente a ella.

\footnotetext{
${ }^{5}$ Natassja Saramago de Araújo Pugliese vincula el pasaje del TIE con el escolio de E, V, 42 (Saramago, 2007, pp. 259-260).

6 “...entiendo por vida humana, aquella que se define no por la sola circulación de la sangre y otras funciones comunes a todos los animales, sino, por encima de todo, por la razón, verdadera virtud y vida del alma" (Spinoza, 1986b, p. 120).
} 


\section{ARTE COMO PRÁCTICA CORPORAL}

La política spinozista es realización del derecho natural y del deseo bajo el modo de las nociones comunes -que, como lo ha mostrado Deleuze (2008, p. 507), no son tanto conceptos matemáticos como categorías prácticas- a la vez que una liberación del arte humano, es decir ejercicio de la vis existendi que adopta la forma de una enmienda de la imaginación, sin no obstante poder nunca prescindir de ella. En tanto concepto ético y político, el arte spinozista -incluidas las "bellas artes", o lo que desde el Romanticismo llamamos simplemente Arte- es práctica inmanente a la vida (el artista -en efecto-en nada piensa menos que en la muerte, y su trabajo es una práctica de la vida y no de la muerte...) que "debe ser hecha por todos", a máxima distancia de cualquier captura en la société du spectacle.

En la naturalidad de su trabajo, el artista spinoziano revierte por antelación cualquier retórica del "genio" para concebirse como "productor" y hacer del arte una experiencia al alcance de cualquiera, o más bien ya en posesión de cualquiera. Si tomamos aquí prestada de Walter Benjamin la expresión "artista como productor" (Benjamin, 1973, pp. 117-134), no es tanto para invocar la necesidad de una "solidaridad con los obreros" (no es tanto, pues, para mostrar que el verdadero artista encuentra su posición en el proceso de producción y que desde allí transforma los medios de producción), como para enfatizar, al revés, que toda potencia, y en sentido máximo la que ha logrado alcanzar una vida activa, es ya artística. Y para constatar que artística es la vida misma que está dada, pero sobre todo la existencia que se vuelve activa, la vida según la razón (o "bajo la guía de la razón": la vida que es capaz de comprender la secuencia del mundo por sus causas, en virtud de condiciones generadas por acumulación de nociones comunes), y en el más alto grado la forma de vida establecida por la scientia intuitiva: la comprensión de las cosas según su esencia, como res singulares que, además de haber sido producidas por una causa también finita, son in Deo. En sintonía aquí con Benjamin -que adjudicaba al fascismo la retórica del "espíritu" (Benjamin, 1973, p. 134)-, ningún "espiritualismo" podrá encontrarse en Spinoza ni en la idea del arte que pueda obtenerse de su filosofía y ninguna "autonomía" del arte respecto de los procesos concretos de la vida y de las acciones concretas de las vidas. En una forma de vida colectiva spinozista que, aún por explorar, lleva el nombre de democracia. La Institución Arte (el Arte como Institución) implosiona en la acción ubicua de los cuerpos, de los "artistas", y de lo que los cuerpos efectivamente hacen.

Tampoco podrá ser concebida en clave espiritualista la ciencia intuitiva, que irrumpe en el corazón de E II. Si bien el así llamado tercer género de conocimiento "progresa a partir de la idea adecuada de la esencia formal de ciertos atributos de Dios, hacia el conocimiento adecuado de la esencia de las cosas" (Spinoza, 1984, p. 157), este proceder - escribe María Jimena Solé en un sugestivo trabajo que seguimos aquí (Solé, 
2013, 2010)- no es deductivo ni presenta pasos intermedios, sino una captación directa de la esencia de las cosas singulares. Se trataría así de un conocimiento inmediato y "fácil de adquirir"; y ello porque la ciencia intuitiva está siempre dada en toda mente humana: no sería tanto o en lo estricto un "conocimiento" sino -como las nociones comunes- una experiencia afectiva y práctica que se inscribe en el orden del deleite: "Nos deleitamos con todo cuanto entendemos según el tercer género de conocimiento, y ese deleite va acompañado por la idea de Dios como causa suya" (Spinoza, 1984, p. 381). De esa experiencia de las cosas - que es intelectual, afectiva y práctica- brota por fuerza un amor intelectual hacia Dios (Spinoza, 1984, p. 382).

En tanto práctica del cuerpo, como potencia adecuada de producir objetos en el orden de la extensión, el arte se corresponde con la ciencia intuitiva en tanto conocimiento de las cosas singulares que conlleva "un conocimiento adecuado e infinito de la esencia de Dios", y ambos se conjugan (o más bien se identifican) en una forma de vida que nombra la expresión "amor intelectual".

\section{MÁS ACÁ DEL ARTE}

Desde una perspectiva que concierne al arte de manera más estricta -tomando a la vanguardia en su positividad y no en cuanto mera contestación de la estética-, JeanFrançois Lyotard (1988) establece una estrecha vinculación de las vanguardias con Kant, en particular con la filosofía de lo sublime expuesta en la Primera Parte de la Crítica del juicio. Si bien el criticismo kantiano restringe el conocimiento a la posibilidad de presentar o representar algo -esto es, pensar según conceptos que pueden aplicarse a la sensibilidad y constituir así la experiencia posible-, sin embargo, los seres humanos tenemos la capacidad, o el desarreglo, según se mire, de concebir cosas que no pueden ser representadas y que no encuentran ninguna verificación sensible. Podemos conocer fenómenos de la naturaleza en la medida en que estos no son refractarios a los conceptos mediante los que conocemos, pero, por ejemplo, no nos será nunca posible conocer el mundo, porque no se da como fenómeno en ninguna experiencia posible. El mundo, sin embargo, puede ser concebido sin que esto signifique ningún aporte para el conocimiento. Lo mismo vale para la idea de infinito, de lo simple, de lo absolutamente grande, etc. Lo que podemos concebir desborda lo que podemos conocer; podemos concebir cosas que son irrepresentables e impresentables.

Sabemos que la vanguardia se constituye como ruptura de la representación, o bien si quisiéramos emplear un término más antiguo, como un abandono de la mimesis. Pero, sin embargo, hay un elemento constructivo en la vanguardia-que, por consiguiente, no se agota en su componente crítico-, y este es el punto en el que reconocerían su matriz en la estética kantiana. Para Lyotard, lo decisivo en el arte moderno -según una comprensión que, por tanto, no opone modernidad y vanguardia, sino que establece entre 


\section{Diego Tatián}

ellas un continuo-, es mostrar lo incognoscible, lo impresentable, lo indecible, lo invisible. El problema fundamental del arte moderno-vanguardista sería, pues, el de presentar lo impresentable. Al evitar la representación, lo impresentable no puede tenerla, la presentación de lo impresentable tendrá la forma de una "presentación negativa", podría pensarse aquí en el Cuadrado negro sobre fondo negro de Alexander Rodchenko o en el Cuadrado blanco sobre fondo blanco de Kasimir Malévich (quien por lo demás llamó a su obra teórica más importante El suprematismo como modelo de la no representación).

Quisiéramos sin embargo proponer un vínculo diferente de la vanguardia con un filósofo moderno -Spinoza-. En este caso, lo central en la comprensión de la vanguardia en su significado más profundo no es su relación con lo impresentable (que Kant llamó "sublime"), ni una presentación de lo que el conocimiento es incapaz de aprehender (el absoluto mismo), sino la constitución de la experiencia como lugar común; o más bien, más allá de los "artistas", el descubrimiento de la banalidad del arte: su facilidad, su facticidad, la extensión y el incremento de su práctica como arte para cualquiera, arte de cualquiera. Así, la filosofía de Spinoza permite concebir al arte de manera desinstitucionalizada, inmanente a la vida de los cuerpos concretos que producen objetos y significados; como avatar de la vida activa (de la "ética") que despoja a la "cultura" de cualquier preceptiva de confiscación en una esfera de exclusividad social, para comprenderla en tanto extensión de la naturaleza, que "es una y la misma en todos" (Spinoza, 1986b, p. 158). Concebido desde la filosofía de Spinoza como acción creadora inmanente a la praxis vital, el arte encuentra pues un campo de reflexión exterior a su establecimiento como institución, y acaso provee una vía olvidada al momento de "autocrítica" por las vanguardias históricas, según la clásica tesis de Peter Bürger en Teoría de la vanguardia:

Solamente desde que el arte se ha separado por completo de toda referencia a la vida práctica, puede reconocerse la progresiva separación del arte respecto al contexto de la vida práctica, y la consiguiente diferenciación simultánea de un ámbito especial del saber (el ámbito de la estética) como principio del desarrollo del arte en la sociedad burguesa (Bürger, 1987, p. 63).

Además de ejercer el "arte" de pulir lentes como modo de ganarse el sustento, Spinoza dibujaba y en su juventud hizo teatro en el taller de su maestro Van den Enden: muy probable que en los años 1657-1658 el joven Baruch actuó en las Troades de Séneca; en el Philedonius del propio Van den Enden; en Andria y Eunnuchus de Terencio (Proietti, 2010). Quizá no resulte tampoco irrelevante que entre 1642 y 1652 -unos años antes de su vínculo con Spinoza-, Van den Enden haya abierto una galería de arte-librería llamada "En la tienda de arte", donde comerciaban cuadros, estatuas, objetos raros, láminas, además de libros e impresiones (que se trataba no solo de una tienda de comercio 
de libros sino sobre todo de una galería de arte es corroborado por el inventario de objetos y piezas realizado con motivo de la liquidación en 1652, conservado en el Archivo de Ámsterdam (Meinsma, 2006, p. 136). Fue tras quebrar con su negocio de arte que estableció en su casa sobre el Singel -uno de los principales canales del centro de Ámsterdam-, la escuela de latín donde frecuentaban jóvenes provenientes de familias liberales que se negaban a educar a sus hijos en las escuelas públicas, muy controladas por el calvinismo ortodoxo (Nadler, 2004, p. 153). Quizá haya que leer sin anacronismos y como un homenaje a su viejo maestro -que al momento de escribir Spinoza estas líneas acababa de ser condenado a muerte en Francia por haberse involucrado en un complot contra Luis XIV al fin desbaratado-el pasaje de TP, VIII, § 49:

Las academias que se fundan con los gastos del Estado, se crean no tanto para cultivar los talentos cuanto para reprimirlos. Por el contrario, en un Estado libre, las ciencias y las artes se cultivan mejor si se permite a todo el mundo que lo pide enseñar públicamente, pero asumiendo él los gastos y el peligro de su reputación (Spinoza, 1986b, pp. 198-199).

En el taller donde se enseñaba en forma libre "las ciencias y las artes" -y no solo la lengua latina-, seguramente Spinoza obtuvo, en efecto, una buena parte de su formación heterodoxa y allí tuvieron origen de sus intereses científicos y estéticos.

Desde su frecuentación del taller vanendeniano Spinoza adoptó un vínculo estrecho con el mundo del arte. El teatro de Ámsterdam había sido fundado por el Dr. Johannes Bouwmeester, médico, latinista y filósofo con quien el autor de la Ética mantuvo una amistad epistolar y personal. Junto con Lodewijk Meyer y otros conocidos de Spinoza-como Antonides van den Goes, con quien había sido condiscípulo la escuela de Van den Enden-, Bouwmeester fundó en 1669 la academia de estudios teatrales Nil Volentibus Arduum, donde no es imposible que Spinoza concurriera en algunas ocasiones. En ese año aún en Voorburg, el filósofo alquilaba un cuarto en la casa del pintor Daniel Tydeman, con quien pudo haber tomado clases de dibujo y bajo cuya guía pudo haber trabajado en el cuaderno que años más tarde Hendryck van der Spyck, también pintor, del que nos ha llegado un retrato de Spinoza (acaso el único de todos los que existen tomado del natural), y dueño de la última casa donde el filósofo se alojó en La Haya, le mostró a Colerus con el presunto autorretrato vestido como Masaniello (Colerus, 1995, p. 110).

Pulir, representar, dibujar, pensar, leer, jugar ajedrez ${ }^{7}$, escribir, activar comunidades y amistades... ¿La de Spinoza fue una forma de vida spinozista? ¿Qué es

\footnotetext{
${ }^{7}$ Según consta en el registro realizado por el notario para proceder a la subasta destinada a pagar los gastos del entierro, entre los objetos hallados en su habitación el día de su muerte, hay uno casi inadvertido y precioso: "un juego de ajedrez en una bolsa". Imaginar a Spinoza ajedrecista evoca una (otra) vida muy distante en el espacio y
} 


\section{Diego Tatián}

una vida spinozista? Vida activa; vida del deseo que no es tanto impulso de autoconservación o perseverancia inercial como deseo de vivir, transindividual, abierto a la experiencia; producción adecuada de ideas, de vínculos y de objetos que no se determinan por su resultado sino por la plenitud inmanente a la vita activa. Una vida sin museo, una vida sin obra - desobrada-, a condición de que el prefijo negativo afecte al sustantivo, no al verbo. Spinozista sería el adjetivo con el que designar una vida más allá de la belleza, más allá del bien, más allá del gusto y más allá del juicio; "pura inmanencia" (Deleuze, 1995, p. 4) que se sustrae a la distinción -y a la existencia misma- del "artista" y la "obra". El arte como forma de vida spinozista no equivale a una "vida de artista"; más bien abre a una práctica de la impropiedad y de la impersonalidad que libera del posesivo, tanto como del culto de sí, y lleva el nombre de ética. En el Prefacio a la edición de las Opera posthuma de 1677, Jarig Jelles transmite la indicación de borramiento de la firma por Spinoza - que la reticencia de sus iniciales solo cumple a medias-. Pero no se trata como lucubra Jelles de modestia ni de humildad, sino de necesidad filosófica estricta contenida en una vida en la inmanencia.

Tanto en la portada como en otros lugares el nombre de nuestro escritor solo es impreso con las iniciales por la sencilla razón de que, poco antes de morir, él mismo expresó el deseo de que no se pusiera su nombre a la Ética, que se disponía a imprimir. Aunque no dio explicación alguna, en nuestra opinión, el único motivo de tal decisión es que no quiso que su doctrina fuera designada con su propio nombre, ya que en el capítulo 23 del Apéndice a la cuarta parte de su Ética afirma que quienes desean ayudar a otros con sus consejos y acciones a disfrutar juntos del sumo bien, no intentarán que su doctrina reciba de ellos su nombre; $y$, además, en la tercera parte de la misma obra, en la explicación de la ambición, tacha abiertamente de ambiciosos a quienes lo hacen (Jelles, 1995, p. 48).

La palabra que confiere título a su obra mayor, se mantiene en Spinoza a máxima distancia de lo que el último Foucault llamaba "arte de la existencia" (techne tou biou), es decir de la ética como "ocupación de sí mismo" según una epiméléia heautou que se aplica a "hacer de la vida una obra de arte" (Foucault, 2003, pp. 38-68).

¿Qué es, entonces, una manera spinozista de vivir? Por cierto no un modo de vida "filosófico", especulativo, sustraído, ni un "cuidado de s's"; tampoco una vida de artista, sino acaso un arte de producir encuentros - con seres, ideas, obras de arte, libros, cosasque generen o prolonguen una potencia intelectual-amorosa de inventar comunidades abiertas, comunidades inconfesables, comunidades de resistencia, comunidades revolucionarias, comunidades irrecíprocas, microcomunidades invisibles... Generación de afectos comunes, nociones comunes y acciones comunes capaces de prosperar por

el tiempo - pero no en la experiencia del arte como ética-; símbolo del paso misterioso de Marcel Duchamp por Buenos Aires, en efecto, el ajedrez ocupa el tiempo de esos días de 1918 y 1919 de los que casi nada se sabe.

304 | Alpha No50 (Julio 2020) PÁGS. 289-307. ISSN 07 16-4254 
acumulación hacia lo que aún no conocemos, y de resistencia a lo que envilece, entristece y bloquea. Acaso un arte de la enmienda (emmendatio es la palabra que usaban los artesanos tipógrafos cuando debían corregir un error sin dañar la página, una intervención delicada y precisa sobre una materia frágil que acoge un sentido en construcción); tal vez una tarea de detección de todo lo que no forma parte de lo que Ítalo Calvino llamaba "el infierno de los vivos". O solo un deseo abierto a la experiencia, atento y agradecido a lo que hay, sin resignación a lo que se impone.

\begin{abstract}
Este texto tuvo origen de un seminario sobre "Spinoza y el arte" dictado en septiembre y octubre de 2018 para la Maestría de estéticas contemporáneas latinoamericanas de la Universidad Nacional de Avellaneda, dirigida por Adrián Cangi y el Centro de Investigaciones Artísticas de Buenos Aires que coordina Roberto Jacoby. Dejo aquí constancia de mi agradecimiento a los participantes del seminario por las observaciones, las discusiones y la intensidad con la que convirtieron a Spinoza en un "bien de uso" para sus propios trabajos en el campo del arte.
\end{abstract}

\title{
OBRAS CITADAS
}

Abdo Ferez, Cecilia (2008). "El concepto de soberanía en Spinoza. Una lectura desde el barroco", en Diego Tatián (editor) Spinoza. Cuarto coloquio. Córdoba: Brujas, Córdoba.

Alters, Svletana (2016). El arte de describir. El arte holandés del XVII. Buenos Aires : Ampersand.

Ansaldi, Saverio (2001). Spinoza et le baroque. Infini, désir, multitude. París: Kimé.

Benjamin, Walter (1973). "El autor como productor" Tentativas sobre Brecht (Iluminaciones III). Madrid: Taurus.

Bozal, Valeriano (1996). "Orígenes de la estética moderna" Historia de las ideas estéticas y de las teorías artísticas contemporáneas, vol. I. Madrid: Visor.

Bürger, Peter (1987). Teoría de la vanguardia. Barcelona: Península.

Colerus, Jean (1995). "Breve, pero fidedigna biografía de Benedictus de Spinoza...”, en Atilano Domínguez (comp.), Biografias de Spinoza. Madrid: Alianza.

Damasio, Antonio (2005). En busca de Spinoza. Neurobiología de la emoción y los sentimientos. Madrid: Crítica.

Deleuze, Gilles (2008). En medio de Spinoza. Buenos Aires: Cactus. (1995). “L'immanence : une vie...”, Philosophie, 47. 
Didi-Huberman, Georges (2018). Ante el tiempo. Historia del arte y anacronismo de las imágenes. Buenos Aires: Adriana Hidalgo.

Domínguez, Atilano (1995). Biografías de Spinoza. Madrid: Alianza.

Dunin Borkowski, Stanislaus (1933). Spinoza. Münster: Aschendorff.

Foucault, Michel (2003). Historia de la sexualidad. 3. La inquietud de sí. Buenos Aires: Siglo XXI.

Gebhardt, Carl (1929). "Rembrandt y Spinoza (contribución histórica al problema del barroco)" Revista de Occidente, XXIII: 307-340.

Hobbes, Thomas (1998). Leviatán. México: Fondo de Cultura Económica.

Jelles, Jarig (1995). “Prefacio de OP (1677)”, en Atilano Domínguez (comp.) Biografías de Spinoza, Madrid : Alianza.

Lagrée Jacqueline (2004). Spinoza et le débat religieux. Lectures du Traité théologicopolitique. Presses Universitaires de Rennes.

Lessing, Gotthold Ephrain (1977). Laocoonte. Madrid: Editora Nacional.

Lezama Lima, José (1993). La expresión americana. México: Fondo de Cultura Económica.

Lyotard, Jean-François (1988). L'inhumain. Causeries sur le temps. Paris: Galilée.

Madanes, Leiser (2001). El árbitro arbitrario. Hobbes, Spinoza y la libertad de expresión. Buenos Aires: Eudeba.

Martin, Jean-Clet (2011). Bréviaire de l'éternité. Vermeer et Spinoza. Paris: Éditions Léo Scheer.

Meinsma, Koenraad Oege (2006). Spinoza et son cercle, Paris : Vrin.Mignini, Filippo (1981) Ars immaginandi. Apparenza e rappresentazione in Spinoza. Napoli : Edizioni Scientifiche Italiane.

Montessori, Maria (1950). Il segreto dell 'infanzia. Milano : Garzanti.

Morrison, James (1989). "Why Spinoza Had No Aesthetics" The Journal fo Aesthetics and Art Criticism, 47 (4): 359-365.

Nadler, Steven (2004). Spinoza. Madrid: Acento.

Plinio el Viejo (1995). Historia natural. Madrid: Gredos.

Proietti, Omero (2010). Philedonius 1657. Spinoza, Van den Enden e I classici latini. Università di Macerata.

Saramago de Araújo Pugliese, Natassja (2007). "Filosofia da Arte na Teoria de Conhecimento de Spinoza", en Diego Tatián (editor), Spinoza. Tercer coloquio. Córdoba: Brujas.

Solé, María Jimena (2013). “La intuición intelectual en Spinoza”, en Diego Tatián (editor), Spinoza. Noveno coloquio. Córdoba: Brujas.

Spinoza, Baruch (2000). Ética demostrada según el orden geométrico. Madrid: Trotta.

_ (1988). Tratado de la reforma del entendimiento. Madrid: Alianza. (1986a). Correspondencia. Madrid: Alianza.

306 | ALPHA No50 (JuLIO 2020) PÁGs. 289-307. ISSN 07 16-4254 
_ (1986b). Tratado político. Madrid: Alianza.

— (1986c). Tratado teológico-político. Madrid: Alianza.

— (1984). Ética demostrada según el orden geométrico. Madrid: Editora Nacional. Steadman, Philip (2011). Vermeer's Camera. Oxford University Press.

Vinciguerra, Lorenzo (2012). La semiotica di Spinoza. Pisa: Edizioni ETS. 